\title{
Education Expenditure and Economic Growth in Mauritius: An Application of the Bounds Testing Approach
}

\author{
Tafirenyika Sunde \\ Professor of Economics, Department of Accounting Economics and Finance \\ Namibia University of Science and Technology (NUST), Namibia
}

doi: 10.19044/esj.2017.v13n22p70 URL:http://dx.doi.org/10.19044/esj.2017.v13n22p70

\begin{abstract}
This study examines the relationship between education expenditure and economic growth in Mauritius. The study employed the ARDL bounds testing methodology for the period 1976 to 2016. The study found that education expenditure Granger causes economic growth in Mauritius in the short run. In addition, the study also found that economic growth does not Granger cause education expenditure in Mauritius in the short run. However, in the long-run, the study found that there are long run relationships between education expenditure and economic growth in both equations; and this means that an increase in either of the variables will eventually lead to an increase in the other variable. The study, therefore, found support for the hypothesis that investment in education raises economic growth. This means that Mauritius has the potential to benefit from further investments in education in the future.
\end{abstract}

Keywords: Education expenditure; economic growth; Granger causality; ARDL; Mauritius

\section{Introduction}

The fact that investment in education is critical for economic growth and social cohesiveness of society is a well-known and widely accepted notion (see Zhang and Zhuang, 2011; Cheong-Cheng, Cheung, and Yeun, 2011; Manafi, and Marinescu, 2013; Burja, and Burja, 2013; Balaev, 2014; Sánchez and Cicowiez, 2014). It should be noted that many of the potential payoffs to society from various types of public investment in education are not instantly obvious, but are significant. In addition to this, there are huge benefits to society in improving the general level of education, because not only the quality of workforce improves, but also because various other aspects such as health, nutrition and sanitation are positively affected, and 
because educated citizens can be more effective participants in a democratic civil society.

Expenditure on education is supposed to bring into the economic system the externalities and other indirect effects, which include successful completion of higher education by young people, lower mortality of children, better individual health and lower number of births. The latter subsequently cause higher productivity in terms of increased earnings and more participation in the labour force. Michaelowa (2000) argued that the resultant lower population growth and better health of population tend to positively cause higher economic growth. It should be noted that the relationship between economic growth and various macroeconomic factors has caught the attention of many economists and policy makers since Adam Smith's time (Tilak, 2005). The macroeconomists have largely concentrated on the effects of government policies on sustainable economic growth. This emphasis can be attributed to the recognition of the fact that the difference between prosperity and poverty in a country depends on how quickly it grows over the long term. Although all the standard macroeconomic policies are important for economic growth, understanding their individual impact on the economic growth is even more significant (Tilak, 2005).

Mauritius has been keen on improving the quality and accessibility of education hence it has provided its citizens with education from primary to tertiary levels. This has led the government to channel the largest proportion of the national budget on average to the Ministries of Education (Ministry of Education and Human Resources and Ministry of Tertiary Education and Scientific Research). This study, therefore, intends to find out if education expenditure has any significant contribution to the national output given the prominence that it has received in the government budget over the years. In addition, the study also wants to find out if the growth in the economy automatically implies increased educational expenditure budget allocations in Mauritius. It should be noted that education of citizens is today not only a right, but also a need since selfimprovement is limited under conditions of illiteracy (Bosupeng and Mpho, 2015). This may contribute to the reduction of poverty rates and further contribute towards the impressive growth path for Mauritius. Mauritius was founded on the principles of multiparty democracy, which can be extrapolated that political disturbances have a limited effect on economic growth (Bosupeng and Mpho, 2015). The study by Bosupeng and Mpho (2015) reported no relationship between education expenditure and economic growth. Mauritius not only prioritises education but as a member state of the United Nations, it has the responsibility to achieve the Millennium Development Goals of which education is one of the key issues that should not be ignored. To this end, governments need not only examine public 
expenditure requirements and the macroeconomic implications of financing them, but also the potential social and economic benefits of associated with them. Despite this, Sánchez and Cicowiez (2014) argued that the benefits of better education and health do not translate into higher productivity instantaneously because students and graduating classes need to go through one or more education cycles for growth to be realised. In addition, Sánchez and Cicowiez (2014) also warned that the contribution of education to Gross Domestic Product (GDP) may also be restricted if the skilled workers remain unemployed.

This paper is an attempt to understand the relationship between government expenditure on education and economic growth in the context of Mauritius. Using time series data from 1976 through 2016 on education expenditure and economic growth in Mauritius, the study examines the causal relationships between these two variables. The empirical methodology adopted for this purpose is the ARDL method, which allows for short- and long run Granger causality analysis. The findings suggest strong evidence for bidirectional causality between economic growths and education expenditure; and there is a long run relationship between the two variables.

The rest of the paper is organised as follows. Section 2 is dedicated a brief review of the literature on the relationship. Next, sections 3 discuss in detail the methodological issues and data sources. Section 4 analyses the test results and interprets them. The last section concludes and gives some possible policy recommendations.

\section{Brief review of literature}

Ali, Hakim and Abdullah (2017) studied the association between government spending on education and economic growth in Pakistan for the period of 1980-2014 using the Johansen cointegration test to find out the long run cointegration relationship among the selected variables. The study also employed the Granger causality test to examine the causal relationship between government spending on education and GDP. The study found a long run positive impact of public education expenditure on GDP. The Granger causality test results show unidirectional causality running from public education expenditure to GDP. A similar study by Adetula, Adesina, Owolabi and Ojeka (2017) found that the education sector contributes significantly to economic development whose proxy was GDP even though the sector is heavily underfunded in Nigeria (especially the basic and senior secondary levels whose enrolments increase yearly even though their infrastructural facilities are poor). In addition, Whalley and Zhao (2013) and Kakar, Khilji, and Khan (2011) also found that human capital plays an important role in China's economic growth. Next Afzal, Malik, Begum, Sarwar and Fatima (2012) also found that education affects economic growth 
positively and significantly only in the long run using the Toda-Yamamoto Augmented Granger Causality methodology.

The following are the other studies that found that education positively impacts economic growth: Benosand Zotou (2014), Mekdad, Dahmani and Louadj (2014), Jalil and Idrees (2013) and Ageli and Moosa (2013). Moreover, Tomić (2015) found a positive correlation between public expenditure on education and GDP in the European Union and BRICS countries. Next, Mallick and Dash (2015) found that a long run equilibrium relationship exists between expenditure on education and economic growth and a unidirectional causality running from expenditure on education to economic growth in India. A different study by Mallick, Dash and Pradhan (2016) used panel data analysis on 14 major Asian countries and found the existence of long-run equilibrium relationships between expenditure on education and economic growth in all the countries. Using panel vector error correction model (PVECM) the study also found unidirectional Granger causality running from economic growth to expenditure on education in both the short- and the long-run. Next, they found that expenditure on education only Granger causes economic growth in long-run in all the countries. Considering all the countries as a group, their results show a positive impact of educational expenditure on economic growth. In addition, Yousif Khalifa Al-Yousif (2008) examined the nature and direction of the relationship between education expenditure as a proxy for human capital and economic growth in the six GCC economies using time-series data for the period 19772004 and found mixed results that vary across both countries and measures of human capital.

Moreover, Bosupeng (2015) studied Botswana one of the highincome economies in Africa just like Mauritius and found no long run relationship between education expenditure and economic growth. Bolkol (2016) also examined the causal relationship between education and economic growth by investigating and comparing the time-series literature, and carrying out a short empirical analysis for Turkey. From the literature survey, he established that causal relationships between education and economic growth are not uniform in different studies. He also found different results compared to other studies that were conducted in Turkey and this was true with regards to the literature survey results for some countries. Tilak (2011) highlighted the fact that the system of higher education in SubSaharan Africa (SSA) is crippled by a wide variety of problems, for example, the erstwhile colonial legacy and the structural adjustment policies, which are purported to retard the growth of higher education in SSA. He added that the other problem that the SSA faces relates to the financing of education, which obviously will have implications on economic growth as mentioned earlier. This article also critically discussed some of the major trends, 
problems and policy issues in financing higher education in SSA, including public financing of higher education, fees, family expenditure and growth of private higher education.

\section{Data and the estimation method}

The empirical literature has provided the basis for the specification of the education expenditure and economic growth relationship in this study. Most previous studies analysed the nexus between education expenditure and economic growth using varied definitions of these variables. Data used for the analysis covers the annual period 1976 to 2016 (40 observations). Quarterly or monthly data are unavailable for these variables. All the data used in this study were obtained from the World Bank's World Development Indicators (CD-ROM). Given the small sample size, the co-integration relationship among the variables in the models is analysed by using the bounds test proposed by Pesaran et.al (2001). The long run models used in this study can thus be specified as follows:

$$
\begin{aligned}
& \mathrm{L}_{-} \mathrm{ECONG}_{t}=\alpha_{0}+\alpha_{1} \mathrm{~L}_{-} \mathrm{EDUE}_{t}+u_{1 t} \\
& \mathrm{~L}_{\mathrm{E}} \mathrm{EDUE}_{t}=\beta_{0}+\beta_{1} \mathrm{~L}_{-} \mathrm{ECONG}_{t}+u_{2 t}
\end{aligned}
$$

where, L_ECONG is economic growth whose proxy is gross domestic product per capita and L_EDUE is eduacation expenditure per capita and $u_{1 t}$ and $u_{2 t}$ are white noise error terms.

$$
\begin{aligned}
& \Delta \mathrm{L} \_\mathrm{ECONG}_{t}=\alpha_{11}+\delta_{12} \mathrm{~L}_{-} \mathrm{ECONG}_{t-1}+\delta_{13} \mathrm{~L}_{-} \mathrm{EDUE}_{t-1} \\
& +\sum_{i=1}^{p} \phi_{1 i} \Delta \mathrm{L}_{-} \mathrm{ECONG}_{t-i}+\sum_{i=1}^{p} \beta_{1 i} \Delta \mathrm{L}_{-} \mathrm{EDUE}_{t-i}+v_{1 t}[3 a] \\
& \Delta \mathrm{L} \_E D U E_{t}=\alpha_{21}+\delta_{22} \mathrm{~L}_{-} \mathrm{ECONG}_{t-1}+\delta_{23} \mathrm{~L}_{-} \mathrm{EDUE}_{t-1} \\
& +\sum_{i=1}^{p} \phi_{2 i} \Delta \mathrm{L}_{-} \mathrm{ECONG}_{t-i}+\sum_{i=1}^{p} \beta_{2 i} \Delta \mathrm{L}_{-} \mathrm{EDUE}_{t-i}+v_{2 t}
\end{aligned}
$$

where $\alpha_{11}$, and $\alpha_{21}$ are the constants for two equations and $\Delta \mathrm{L} \_$ECONG, and $\Delta \mathrm{L} \_E D U E$ are first differences of logarithms of economic growth and education expenditure, respectively. In addition, $v_{1 t}$ and $v_{2 t}$ are white noise error terms. We can test for cointegration between $\mathrm{L}_{-} \mathrm{EDUE}_{t}$ and $\mathrm{L}_{-} \mathrm{ECONG}_{t}$ using the Bounds testing approach. For equations [3a] and [3b], the F-test (normal Wald test) is used for investigating one or more long run relationships. In the case of one or more long run relationships, the F-test indicates which variable should be normalised (Koop, 2005).

In equation [3a] when $\mathrm{L}_{-} \mathrm{ECONG}_{t}$ is the dependent variable the null hypothesis of no cointegration is $H_{0}: \delta_{12}=\delta_{13}=0$ and the alternative hypothesis of cointegration is $H_{1}: \delta_{12} \neq \delta_{13} \neq 0$. In equation [3b], the null 
hypothesis of no cointegration is $H_{0}: \delta_{22}=\delta_{23}=0$ and the alternative hypothesis of cointegration is $H_{1}: \delta_{22} \neq \delta_{23} \neq 0$. The distribution of Fstatistic developed by Pesaran et al. (2001) is non-standard. The reason being that the F-statistic is based on the assumption that variables are integrated at $\mathrm{I}(0)$ or I(1). If the calculated F-statistic is less than the lower critical bound (LB), then the hypothesis of no cointegration may be accepted. Cointegration may be found if the calculated F-statistic exceeds the upper critical bound (UB). In addition, the long run relation is inconclusive if the calculated Fstatistic lies between the lower and the upper critical values.

Following Odhiambo (2017), Sunde (2017), Goh, Sam and McNown (2017) a multivariate causality model for the current study based on error correction modelling can be expressed as follows:

$$
\begin{aligned}
\Delta \mathrm{L}_{-} \mathrm{ECONG}_{t}= & \sum_{i=1}^{p} \phi_{1 i} \Delta \mathrm{L}_{-} \mathrm{ECONG}_{t-i} \\
& +\sum_{i=1}^{p} \beta_{1 i} \Delta \mathrm{L}_{-} \mathrm{EDUE}_{t-i}+\theta_{2} \mathrm{ECT}_{t-1}+e_{1 t} \quad[4 a]
\end{aligned}
$$

$\Delta \mathrm{L}_{-} \operatorname{EDUE}_{\mathrm{t}}=\sum_{\mathrm{i}=1}^{\mathrm{p}} \phi_{2 \mathrm{i}} \Delta \mathrm{L}_{-} \mathrm{ECONG}_{\mathrm{t}-\mathrm{i}}$

$$
+\sum_{\mathrm{i}=1}^{\mathrm{p}} \beta_{2 \mathrm{i}} \Delta \mathrm{L}_{-} \text {EDUE }_{\mathrm{t}-\mathrm{i}}+\theta_{3} \mathrm{ECT}_{\mathrm{t}-1}+\mathrm{e}_{2 \mathrm{t}}
$$

where $\mathrm{ECT}_{t-i}$ is the error correction term lagged once and $e_{1 t}$ and $e_{2 t}$ are white noise error terms. The null hypotheses that education expenditure does not Granger cause economic growth is given by $H_{0}: \sum_{i=1}^{p} \beta_{1 i}=0$ and the alternative is $H_{1}: \sum_{i=1}^{p} \beta_{1 i} \neq 0$. Similarly, the null hypothesis that economic growth does not Granger cause education expenditure is $H_{0}: \sum_{\mathrm{i}=1}^{\mathrm{p}} \phi_{2 \mathrm{i}}=0$ and the alternative hypothesis is $H_{1}: \sum_{\mathrm{i}=1}^{\mathrm{p}} \phi_{2 \mathrm{i}} \neq 0$. The negative signs and the significance of the coefficients of $\mathrm{ECT}_{\mathrm{t}-1}$ confirm the existence of the long run relationships found using equations [3a] and [3b].

\section{Empirical Analysis \\ Non-stationarity tests}

The first step taken in the analysis of the results was to transform GDP per capita (the proxy for economic growth) and education expenditure per capita to logarithms and test them for non-stationarity. The logarithms of the variables and their first differences were plotted against time to determine the nature of their trends and this is an informal method of 
determining non-stationarity. Figure 1 shows that the logarithms of the variables have upward trends and this suggests that the variables may have unit roots. This is confirmed by the figures of the first differences of the two variables in Figure 1, which manifestly indicate that the variables have no clear-cut trends after they have been differenced. Second, the study carried out some formal non-stationarity tests using the Augmented Dickey Fuller (ADF) and the Phillips Peron (PP) tests. The results in Table 1 clearly show that both variables are non-stationary in levels, but they become stationary at the 1 percent level of significance after first differencing using both the ADF and the PP methods. This unambiguously corroborates the informal test that found that the variables are non-stationary in levels and are stationary in first differences.
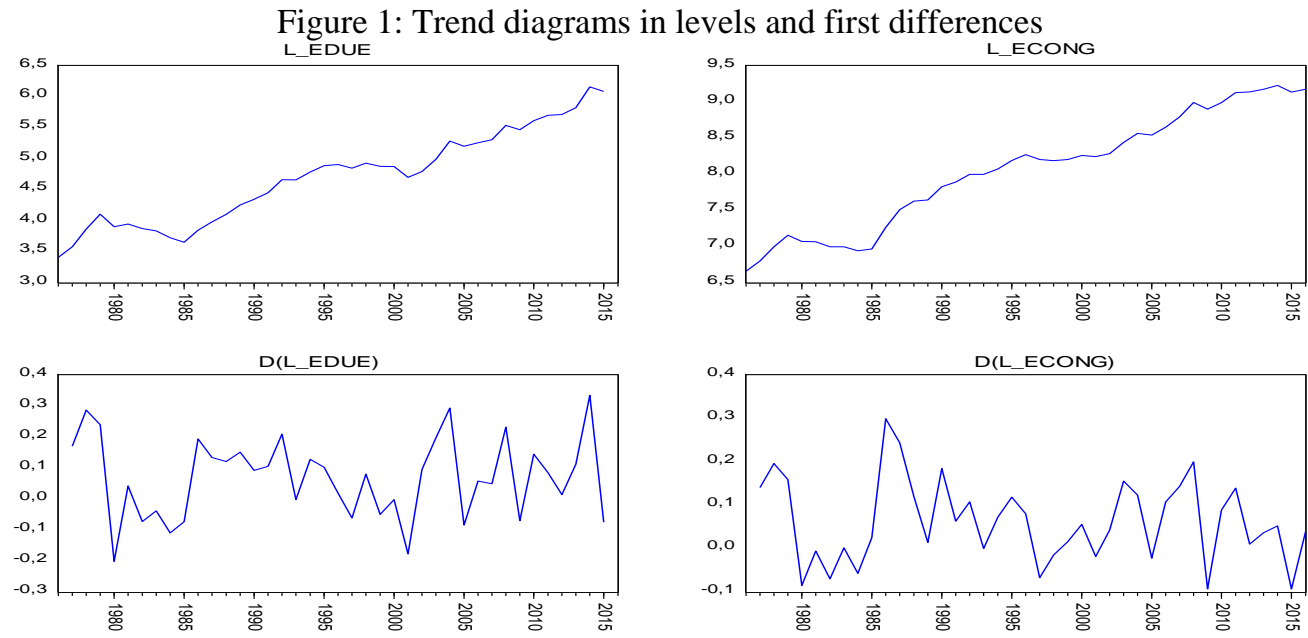

Table 1: Augmented Dickey Fuller Test Results

\begin{tabular}{|c|c|c|c|c|}
\hline Variable & Model & Log-level & First Difference & Decision \\
\hline \multicolumn{5}{|c|}{ Augmented Dickey Fuller (ADF) Test } \\
\hline \multirow[t]{2}{*}{ L_ECONG } & Intercept & -1.72334 & $-5.8412 * * *$ & $\mathrm{I}(1)$ \\
\hline & Intercept and trend & -1.85353 & $-5.7658 * * *$ & $\mathrm{I}(1)$ \\
\hline \multirow[t]{2}{*}{ L_EDUE } & Intercept & -0.445313 & $-5.6662 * * *$ & $\mathrm{I}(1)$ \\
\hline & Intercept and trend & -2.393771 & $-5.5974 * * *$ & $\mathrm{I}(1)$ \\
\hline \multicolumn{5}{|c|}{ Phillips Peron (PP) Test } \\
\hline \multirow[t]{2}{*}{ L_ECONG } & Intercept & -1.44478 & $-5.94281 * * *$ & $\mathrm{I}(1)$ \\
\hline & Intercept and trend & -1.56479 & $-6.33886 * * *$ & $\mathrm{I}(1)$ \\
\hline \multirow[t]{2}{*}{ L_EDUE } & Intercept & -0.468074 & $-5.64167 * * *$ & $\mathrm{I}(1)$ \\
\hline & Intercept and trend & -2.551514 & $-5.56583 * * *$ & $\mathrm{I}(1)$ \\
\hline
\end{tabular}

Notes: *** denotes significance at $1 \%$, level. 


\section{Co-integration analysis}

Table 2 shows that the computed F-statistic for the economic growth equation is 6.02 , which is higher than the upper bound critical values at $10 \%$, $5 \%$ and $1 \%$ levels of significance. Additionally, Table 2 also shows that the F-statistic for the education expenditure equation is 9.64 , which is higher than the upper bound critical values at $10 \%, 5 \%$ and $1 \%$ levels of significance. This means that there is cointegration (long-run relationship) between economic growth and education expenditure and the variables that explain them.

Table 2: Bounds Test for Cointegration

\begin{tabular}{|c|c|c|c|c|c|c|}
\hline Dependent Variable & \multicolumn{4}{|c|}{ Function } & \multicolumn{2}{|c|}{ F-statistic } \\
\hline L_ECONG & \multicolumn{4}{|c|}{ F(L_ECONG| L_EDUE) } & \multicolumn{2}{|c|}{$6.019047 * * *$} \\
\hline L_EDUE & \multicolumn{4}{|c|}{ F(L_EDUE|L_ECONG) } & \multicolumn{2}{|c|}{$9.644414 * * *$} \\
\hline \multicolumn{7}{|c|}{ Asymptotic critical values } \\
\hline & \multicolumn{2}{|c|}{$1 \%$} & \multicolumn{2}{|c|}{$5 \%$} & \multicolumn{2}{|c|}{$10 \%$} \\
\hline \multirow{2}{*}{$\begin{array}{c}\text { Critical Value } \\
\text { Bounds } \\
\end{array}$} & LB & UB & LB & UB & LB & UB \\
\hline & 3.65 & 4.66 & 2.79 & 3.67 & 2.37 & 3.20 \\
\hline
\end{tabular}

Notes: *** denotes significance at $1 \%$ level. LB and UB stand for Lower Bound and Upper Bound, respectively.

\section{Granger causality analysis}

Table 3 presents the Granger causality test results for both the economic growth equation and the education expenditure equation. First, the results reject the null hypothesis that education expenditure does not Granger cause economic growth. Second, the results fail to reject the null hypothesis that economic growth does not Granger cause education expenditure. These results show that there is unidirectional causality between economic growth and education expenditure in Mauritius running from education expenditure to economic growth. These results corroborate the results from studies by Ali et.al (2017), Adetula et.al (2017), Whalley and Zhao (2013) and Kakar et.al (2011) who also found that education expenditure impacts economic growth and not the other way around. Moreover, these results at variance with what Bosupeng (2015) found for Botswana (a middle-income country in Southern Africa). The study by Bosupeng (2015) found that education expenditure and economic growth are independent of each other in Botswana. It should be noted that results obtained for some countries by different researchers, using different methodologies and different periods were conflicting.

Table 3: Short-run and Long-run Granger Causality

\begin{tabular}{|c|c|c|c|}
\hline \multirow{2}{*}{ Dependent Variable } & \multicolumn{2}{|c|}{ Short run causality } & Long run causality \\
\cline { 2 - 4 } & \multicolumn{2}{|c|}{ F-statistic (Probability) } & \multirow{2}{*}{$\begin{array}{c}\text { ECT }_{\mathrm{t}-1} \\
\text { (t-statistic) }\end{array}$} \\
\cline { 2 - 4 } & $\Delta \mathrm{L}$ ECONG & $\Delta \mathrm{L}$ EDUE & $-0.447^{* * *}$ \\
& - & $20.445^{* * *}$ & $(0.0000)$ \\
\hline$\Delta$ L_ECONG & & - & $-0.347 * * *$ \\
& 1.732 & & $(-4.834)$ \\
\hline
\end{tabular}




\section{Robustness checks}

To test for the robustness of the results obtained, the study used tests for autocorrelation, normality, misspecification, and heteroscedasticity (see Table 4). First, the coefficients of determination of for both equations are above $60 \%$, which is considered as the cut-off for good models. Second, the Durbin-Watson statistic and the Breush-Godfrey LM test show that both equations do not suffer from autocorrelation. Third, the study fails to reject the null hypothesis of normally distributed residuals in both equations using the Jarque-Bera normality test. Next, the study fails to reject the null hypothesis of homoscedastic residuals in both equations using the ARCH test. Fifth, the Ramsey RESET test indicates an absence of the general specification error in both models. The estimated models were also subjected to the CUSUM and CUSUM of squares to check the parameter stability of equations. Both models appear to be correctly specified and generally stable as neither the CUSUM and CUSUM of squares exceeded the bounds of $5 \%$ level of significance as illustrated in figures 2 and 3. The results obtained using all these tests confirm that findings are reliable and robust.

Table 4: Diagnostic Tests

\begin{tabular}{|c|c|}
\hline \multicolumn{2}{|c|}{ Dependent Variable: $\Delta$ L_ECONG } \\
\hline Adjusted R-squared & 0.790349 \\
\hline Durbin-Watson stat & 1.695197 \\
\hline Ramsey REST test $(2)$ & $0.282378(0.6041)$ \\
\hline Jarque-Bera test & $0.816004(066498)$ \\
\hline Breush-Godfrey LM test & $1.024672(0.3883)$ \\
\hline ARCH test (2) & $0.177120(0.6770)$ \\
\hline
\end{tabular}

Dependent Variable: $\Delta$ L_EDUE

\begin{tabular}{|c|c|}
\hline Adjusted R-squared & 0.679986 \\
\hline Durbin-Watson stat & 1.864796 \\
\hline Ramsey REST test (2) & $1.270690(0.2744)$ \\
\hline Jarque-Bera test & $1.227687(0.541283)$ \\
\hline Breush-Godfrey LM test & $0.078716(0.9246)$ \\
\hline ARCH test (2) & $0.081357(0.7772)$ \\
\hline
\end{tabular}


Figure 2: Plots of CUSUM and CUSUM of Squares for Economic Growth

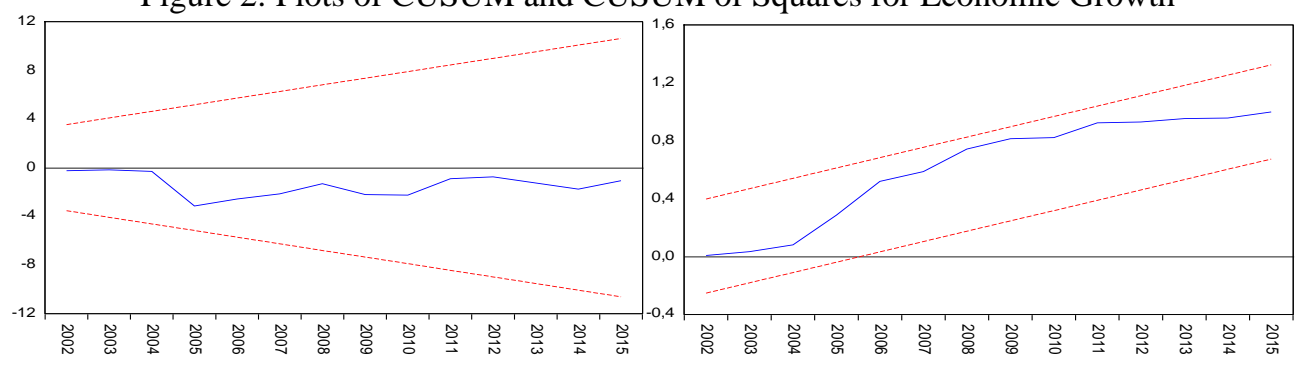

- cusum $-\ldots$.- $5 \%$ significance

- cusum of Squares ---- $5 \%$ Significance

Figure 3: Plots of CUSUM and CUSUM of Squares for Education Expenditure
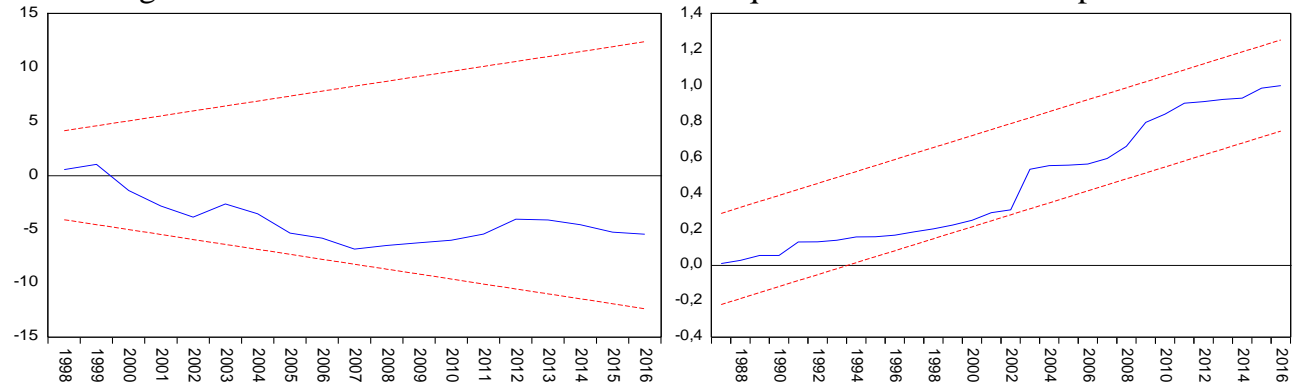

- CUSUM ----- 5\% Significance

\section{Conclusion and recommendations}

From the results obtained in section 4, we first conclude that education expenditure Granger causes economic growth in Mauritius in the short run. Second, we also conclude that economic growth does not Granger cause education expenditure in Mauritius in the short run. However, in the long-run, the study found that there are long run relationships between education expenditure and economic growth in both equations; and this means that an increase in either of the variables will eventually lead to an increase in the other variable. We find support for the hypothesis that some investments in education raise economic growth. This means that Mauritius can benefit from further investments in education in the future. Since the results obtained from literature analysis for some countries by different researchers, using different methodologies and different periods were conflicting, we recommend that future researchers should use panel data covering the same period for different countries.

\section{References:}

1. Adetula, D. T., Adesina, K., Owolabi, F., \& Ojeka, S. (2017). Investment in Education for the Nigerian Economic Development. Journal of Internet Banking and Commerce. 
2. Afzal, M., Malik, M. E., Begum, I., Sarwar, K., \& Fatima, H. (2012). Relationship among education, poverty and economic growth in Pakistan: an econometric analysis. Journal of Elementary Education, 22(1), 23-45.

3. Ageli, M. M. (2013). Does education expenditure promote economic growth in Saudi Arabia? An Econometric Analysis.

4. Ali, A., Hakim, R. A. \& Abdullah, H. (2017). Relationship between Government spending on education and economic growth of Pakistan. Asian Journal of Multidisciplinary Studies, 5(2).

5. Al-Yousef, Y. K. (2011). The Gulf Cooperation Council (GCC) countries and the triangle of autocracy, oil and foreign powers. Contemporary Arab Affairs, 4(1), 19-29.

6. Benos, N. \& Zotou, S. (2014). Education and economic growth: A meta-regression analysis. World Development, 64, 669-689.

7. Bolkol, H. K. (2016). Do Time Series Analyses Provide Consensus About the Relationship between Education and Economic Growth? International Journal of Business Management \& Economic Research, 7(5).

8. Bosupeng, M. (2015). Payoffs of Education Expenditure in Botswana: Long Run Economic Growth Implications, pp 85-96.

9. Goh, S. K., Sam, C. Y. \& McNown, R. (2017). Re-examining Foreign Direct Investment, Exports, and Economic Growth in Asian Economies Using a Bootstrap ARDL Test for Cointegration. Journal of Asian Economics.

10. Jalil, A., \& Idrees, M. (2013). Modelling the impact of education on the economic growth: Evidence from aggregated and disaggregated time series data of Pakistan. Economic Modelling, 31, 383-388.

11. Kakar, Z. K., Khilji, B. A. \& Khan, M. J. (2011). Relationship between education and economic Growth in Pakistan: A time series analysis. Journal of International Academic Research, 11(1), 27-32.

12. Mallick, L. \& Dash, D. P. (2015). Does Expenditure on Education Affect Economic Growth in India? Evidence from Cointegration and Granger Causality Analysis. Theoretical \& Applied Economics, 22(4).

13. Mekdad, Y., Dahmani, A., \& Louaj, M. (2014). Public spending on education and economic growth in Algeria: Causality test. International Journal of Business and Management, 2(3), 55.

14. Pesaran, M. H., Shin, Y. \& Smith, R. J. (2001). Bounds testing approaches to the analysis of level relationships. Journal of applied econometrics, 16(3), 289-326. 
15. Pesaran, M. H., Shin, Y. \& Smith, R. P. (1999). Pooled mean group estimation of dynamic heterogeneous panels. Journal of the American Statistical Association, 94(446), 621-634.

16. Sánchez, M. V., \& Cicowiez, M. (2014). Trade-offs and payoffs of investing in human development. World Development, 62, 14-29.

17. Sunde, T. (2017). Foreign direct investment, exports and economic growth: ADRL and causality analysis for South Africa. Research in International Business and Finance, 41, 434-444.

18. Tilak, J. B. (2011). Financing higher education in Sub-Saharan Africa. Africanus, 41(2), 4-31.

19. Tomić, Z. (2015). Analysis of the Impact of Public Education Expenditure on Economic Growth of European Union and BRICS. Economic analysis, 48(1-2), 19-38.

20. Whalley, J. \& Zhao, X. (2013). The contribution of human capital to China's economic growth. China Economic Policy Review, 2(01), 1350001.

21. Zhang, C. \& Zhuang, L. (2011). The composition of human capital and economic growth: Evidence from China using dynamic panel data analysis. China Economic Review, 22(1), 165-171.

22. Cheong Cheng, Y., Cheung, A. C. \& Yeun, T. W. (2011). Development of a regional education hub: The case of Hong Kong. International Journal of Educational Management, 25(5), 474-493.

23. Manafi, I. \& Marinescu, D. E. (2013). The Influence of Investment in Education on Inclusive Growth-Empirical Evidence from Romania vs. EU. Procedia-Social and Behavioural Sciences, 93, 689-694.

24. Burja, C. \& Burja, V. (2013). Education's contribution to sustainable economic growth in Romania. Procedia-Social and Behavioural Sciences, 81, 147-151.

25. Balaev, M. (2014). Improving models of democracy: the example of lagged effects of economic development, education, and gender equality. Social science research, 46, 169-183.

26. Bosupeng, M. (2015). Payoffs of Education Expenditure in Botswana: Long Run Economic Growth Implications. University Library of Munich, Germany. 